\title{
OS COORDENADORES DE ÁREA DO PIBID: PERCEPÇÕES SOBRE O SER PROFESSOR FORMADOR
}

\author{
Celia Maria Fernandes Nunes ${ }^{1}$, Fernanda Karine Moura Silva Sales ${ }^{2}$
}

${ }^{1}$ Pós Doutorado pela Universidade Federal de Minas Gerais - UFMG e Universidad Nacional de General Sarmiento. Doutorado em Educação pela Pontifícia Universidade Católica do Rio de Janeiro - PUC/RJ. Professora Titular e docente do Programa de Pós-Graduação em Educação do Instituto de Ciências Humanas e Sociais da Universidade Federal de Ouro Preto UFOP, MG. ORCID iD: https://orcid.org/0000-0002-2338-1876 E-mail: cmfnunes1@gmail.com

${ }^{2}$ Mestre em Educação pelo Programa de Pós-Graduação em Educação do Instituto de Ciências Humanas e Sociais da Universidade Federal de Ouro Preto UFOP, MG. Coordenadora da Educação Infantil na Secretaria de Educação do Município de Santa Luzia, MG. ORCID iD: https://orcid.org/0000-0002-8393-3599 E-mail: fernandakarine93@gmail.com

\section{RESUMO}

A formação de professores é uma temática que permeia o campo de estudos na área da educação, bem como as políticas educacionais. Dentre as políticas, ressaltamos o Programa Institucional de Bolsa de Iniciação à Docência (PIBID) que consiste em uma ação indutiva na formação de professores objetivando valorizar e melhorar a formação docente. O programa é desenvolvido em parceria com universidades e escolas de educação básica e envolve licenciandos, supervisores (professores da educação básica), coordenadores de área e professores que atuam na coordenação institucional e na gestão dos processos educacionais (professores do ensino superior). Esse artigo faz parte de uma pesquisa qualitativa que buscou investigar a relação entre a formação e a prática docente na percepção dos coordenadores de área do PIBID/Universidade Federal de Ouro Preto (UFOP). Neste artigo, apresentamos a análise dos dados coletados, por meio de questionários e entrevistas, referentes à categoria: "O que é ser professor e formador de professores". Dentre as percepções foi possível identificar que os coordenadores de área do PIBID/UFOP estão em formação permanente e o PIBID foi uma possibilidade de aproximação com a escola pública de educação básica. $O$ estudo permitiu-nos concluir ainda que há uma reciprocidade formativa entre os participantes, onde além de formarem também são formados. Os coordenadores de área reforçaram a concepção do conhecimento e do tato pedagógico alinhados à indissociação da teoria e da prática, o trabalho do formador pautado no diálogo, no compromisso com a educação pública, a formação de professores, com o ensino e aprendizagem e com a constante reavaliação de sua própria prática.

Palavras-chave: Coordenadores de área. PIBID. Formação de professores. Formadores de Professores.

\section{PIBID AREA COORDINATORS: PERCEPTIONS ABOUT THE TRAINING TEACHER}

\section{ABSTRACT}

Teacher training is a theme that permeates the field of studies in the field of education, as well as educational policies. Among the policies, we highlight the Institutional Teaching Initiation Scholarship Program (PIBID), which consists of an inductive action in the training of teachers aiming to value and improve teacher training. The program is developed in partnership with Universities and Basic Education Schools and involves graduates, supervisors (basic education teachers), area coordinators and teachers who work in institutional coordination and in the management of educational processes (higher education teachers). This article is part of a qualitative research that sought to investigate the relationship between training and teaching practice in the perception of the area coordinators of PIBID / Federal University of Ouro Preto (UFOP). In this article, we will present the analysis of the data collected, through questionnaires and interviews, referring to the category: "What it is to be a teacher and teacher trainer". Among the perceptions, it was possible to identify that the PIBID / UFOP area coordinators are in permanent training and the PIBID was a possibility of approaching the public school of basic education. The study allowed us to conclude that there is a formative reciprocity among the participants, which as they form. The area 
coordinators reinforced the conception of knowledge and pedagogical tact in line with the inseparation of theory and practice, the work of the trainer based on dialogue, commitment to public education, teacher training, teaching and learning and the constant reassessment of its own practice.

Keywords: Area coordinators. PIBID. Teacher training. Teacher Trainers.

\section{COORDINADORES DE ÁREA PIBID: PERCEPCIONES SOBRE EL PROFESOR EN FORMACIÓN}

\section{RESUMEN}

La formación del profesorado es un tema que permea el campo de estudios en el campo de la educación, así como las políticas educativas. Entre las políticas, destacamos el Programa de Becas de Iniciación Docente Institucional (PIBID), que consiste en una acción inductiva en la formación de docentes con el objetivo de valorar y mejorar la formación docente. El programa se desarrolla en alianza con Universidades y Escuelas de Educación Básica e involucra a egresados, supervisores (docentes de educación básica), coordinadores de área y docentes que trabajan en la coordinación institucional y en la gestión de los procesos educativos (docentes de educación superior). Este artículo es parte de una investigación cualitativa que buscó indagar en la relación entre la formación y la práctica docente en la percepción de los coordinadores de área del PIBID / Universidad Federal de Ouro Preto (UFOP). En este artículo presentaremos el análisis de los datos recolectados, a través de cuestionarios y entrevistas, haciendo referencia a la categoría: "Qué es ser docente y formador de docentes". Entre las percepciones se pudo identificar que los coordinadores de área PIBID / UFOP están en formación permanente y el PIBID era una posibilidad de acercamiento a la escuela pública de educación básica. El estudio permitió concluir que existe una reciprocidad formativa entre los participantes, que a medida que se forman. Los coordinadores de área reforzaron la concepción de conocimiento y tacto pedagógico en línea con la teoría y práctica inseparables, el trabajo del formador basado en el diálogo, el compromiso con la educación pública, la formación docente, la enseñanza y el aprendizaje y la reevaluación constante de la propia práctica.

Palabras clave: Coordinadores de área. PIBID. Formación de profesores. Formadores de profesores.

\section{INTRODUÇÃO}

As políticas de formação de professores é um tema recorrente nas discussões acadêmicas e, no debate público. A preocupação em formar professores está presente desde Comenius no século XVII até os dias de hoje. Os cursos de formação de professores, desde a sua criação, com o curso de primeiras letras no século XIX, passam por transformações, concomitantemente, com as mudanças sociais, históricas e políticas.

Numa breve retomada histórica, identificamos que os cursos de formação de professores, na década de 70 , eram conhecidos pelo seu caráter "técnico", que posteriormente, na década de 80 , enfatizou a docência como base da formação, enfoque novamente alterado em 1990, quando a concepção de professor pesquisador ganhou espaço (LÜDKE, 2001). Para além dos enfoques dados em cada um desses períodos, Nóvoa (2017, p. 1114) enfatiza a importância das instituições formadoras, pois "elas refletem os profissionais que formam". Em virtude disso reconhece que a escola, a universidade e os profissionais atuantes na formação docente são essenciais neste processo formativo.

Assim, pensando na formação de professores e, visando a valorização da docência, o Ministério da Educação (MEC), financiou em 2007, por meio da Coordenação de Aperfeiçoamento de Pessoal de Nível Superior (CAPES), o Programa Institucional de Bolsa de Iniciação à Docência (PIBID) como uma ação indutora de políticas públicas de formação de professores, programa este desenvolvido pela Diretoria de Educação Básica (DEB) em parceria com as instituições de ensino superior (IES).

No que tange ao PIBID, algumas etapas são importantes para a compreensão sobre o seu funcionamento e estrutura, como: a instituição de ensino superior quando interessada em participar do programa, submetia um projeto institucional à CAPES, que após aprovação, é desenvolvido nas IES e nas escolas de educação básica. $O$ desenho organizacional deste programa contempla: um coordenador institucional (professor da IES); coordenador de gestão de processos educacionais (professor/es da IES que auxiliam o coordenador institucional); coordenadores de área (professores 
da IES que atuam na gestão de cada subprojeto por área); supervisor (professor da educação básica atuante na escola parceira por área) e o bolsista de iniciação à docência (licenciando).

Em 2009, muitas instituições de ensino superior tiveram suas propostas de projetos institucionais aprovadas pela CAPES, dentre elas, a Universidade Federal de Ouro Preto (UFOP). Assim, a Universidade Federal de Ouro Preto foi consolidando o programa exponencialmente ao longo dos anos.

Segundo Rosa e Matos (2015) o PIBID/UFOP, inicialmente era intitulado como "Projeto Estímulo a Docência (PED)" e contava com a parceria de 9 escolas na cidade de Ouro Preto, 10 em Mariana, totalizando 16 subprojetos em áreas diferentes. Estes subprojetos eram geridos pelos coordenadores de área e ofereciam 219 bolsas de iniciação à docência para licenciandos e 41 supervisores (professores das escolas). Os autores salientam que em 2013 o programa contava com dois coordenadores institucionais e dois coordenadores de área de gestão de processos educacionais, contemplando todos os cursos de licenciatura na modalidade presencial da universidade.

Os coordenadores de área são, sobretudo, professores no ensino superior. Serão eles responsáveis por parte da mediação pedagógica e acadêmica dos estudantes. Estes profissionais possuem um importante papel de transformação e construção da identidade docente, inclusive dos licenciandos que estão em formação, ao qual nos referimos, que estão na formação inicial e serão futuros professores.

Reconhecemos que os professores do ensino superior também foram formados por outros professores, a partir de concepções de cursos de formação, oriundos de épocas e contextos históricos diferentes dos seus. Esta diferença geracional se manifesta como um processo presente na interação entre profissionais em formação e formadores. Mizukami (2005) aponta que é importante que os formadores de professores rompam com alguns paradigmas de sua própria formação, para conseguirem lidar com o novo contexto da formação docente contemporânea.

Nesse sentido, O PIBID, colabora para a formação inicial dos estudantes, bem como para a transformação do olhar dos professores da educação básica (supervisores) que estão em exercício e, na formação dos professores no ensino superior (coordenadores de área), que tem a possibilidade de repensar e ressignificar a sua prática, por meio do diálogo com os participantes do programa.

Considerando a importância do programa e da interação entre estudantes e formadores, este artigo busca evidenciar como os coordenadores de área do PIBID/UFOP percebem o seu papel como formadores de professores. Buscamos assim, à luz de Mizukami (2005) um suporte de análise sobre a aprendizagem da docência, como também recorrermos a Freire (1996) para subsidiar o diálogo da formação permanente e, ainda utilizamos Nóvoa (2009, 2017) na discussão da formação docente no contexto da profissão.

\section{DELINEAMENTO METODOLÓGICO}

A metodologia da pesquisa utilizada foi de cunho qualitativo pois, como Minayo (2001, p. 22) esclarece, essa abordagem "aprofunda-se no mundo dos significados das ações e relações humanas, um lado não perceptível e não captável em equações, médias e estatísticas". Para tanto, utilizamos questionário e entrevista como instrumentos para a coleta de dados.

Recorremos à entrevista semiestruturada por ser uma oportunidade de "interação social mais dinâmica" (MINAYO, 2016, p. 60) e proporcionar questionamentos básicos que se relacionam com o tema de pesquisa (TRIVIÑOS, 1987, p. 152), também utilizamos questionário por auxiliar no delineamento do perfil dos participantes da pesquisa e o currículo lattes quando as informações do questionário estavam incompletas ou de difícil compreensão.

Para escolha dos participantes da pesquisa usamos como critério os coordenadores de área que possuíam a formação específica, experiência na licenciatura/docência e que haviam atuado no programa por ao menos três anos. Assim, elegemos treze professores da UFOP que foram bolsistas de coordenação de área no PIBID/UFOP. Como apresentamos na tabela a seguir: 
Tabela 1. Os participantes do PIBID/UFOP Edital 061/2013

\begin{tabular}{|c|c|c|c|c|}
\hline Pseudônimos & Subprojeto/área & $\begin{array}{l}\text { Mês de } \\
\text { Início das } \\
\text { atividades }\end{array}$ & $\begin{array}{l}\text { Mês de } \\
\text { Término das } \\
\text { atividades }\end{array}$ & $\begin{array}{l}\text { Total } \\
\text { meses } \\
(+36)\end{array}$ \\
\hline Flávia & Letras 1 & $03 / 2014$ & $02 / 2018$ & 48 \\
\hline Jonatas & Letras 2 & $03 / 2014$ & $02 / 2018$ & 48 \\
\hline Audineta & Música & $03 / 2014$ & $08 / 2017$ & 41 \\
\hline Deise & Química & $02 / 2015$ & $02 / 2018$ & 36 \\
\hline Dorcelina & Pedagogia/EJA & $08 / 2014$ & $02 / 2018$ & 42 \\
\hline Helton & Teatro & $03 / 2014$ & $02 / 2018$ & 48 \\
\hline Lucio & Educação Física & $11 / 2014$ & $02 / 2018$ & 39 \\
\hline Maria & Pedagogia/Inclusão & $03 / 2014$ & $02 / 2018$ & 48 \\
\hline Miguel & Pedagogia/Alfabetização & $03 / 2014$ & $02 / 2018$ & 48 \\
\hline Natércio & Matemática & $03 / 2014$ & $02 / 2018$ & 48 \\
\hline Oleir & Historia & $03 / 2014$ & $02 / 2018$ & 48 \\
\hline Renata & $\begin{array}{ll}\text { Interdisciplinar } & \text { Literatura } \\
\text { Afrobrasileira } & \\
\end{array}$ & $03 / 2014$ & $08 / 2017$ & 41 \\
\hline Wilson & Interdisciplinar Ciências & $03 / 2014$ & $02 / 2018$ & 48 \\
\hline
\end{tabular}

Fonte: As autoras.

Todos os coordenadores de área convidados, colaboraram voluntariamente com a pesquisa e assinaram o Termo de Consentimento Livre e Esclarecido, uma carta de anuência e um questionário para delimitação do perfil. A fim de manter o rigor ético e científico, conforme o projeto da pesquisa aprovado pelo Comitê de Ética em Pesquisa (CEP/UFOP), atendendo às orientações da Comissão de Ética em Pesquisa (CONEP), as identidades dos participantes foram preservadas e os nomes foram substituídos por nomes fictícios.

Apoiamos a um roteiro de entrevista como ferramenta norteadora para o cumprimento do nosso objetivo, porém, não interferimos na autonomia e liberdade dos participantes, buscamos minimizar da maior forma possível a interferência durante a construção dos argumentos dos coordenadores de área.

Após os dados coletados, as entrevistas foram transcritas integralmente e recorremos a análise de conteúdo de Bardin (2011), pois os fundamentos para a análise podem ser aplicados aos discursos considerando os seus aspectos diversificados.

A análise e a discussão dos dados permitem a interpretação de maneira dialética, como esclarece Minayo (2001, p. 68) "a análise e a interpretação estão contidas no mesmo movimento: o de olhar atentamente para os dados da pesquisa".

A partir da análise de conteúdo das entrevistas, organizamos os dados buscando relacionar as temáticas através de categorias e, incluindo nelas os assuntos abordados. Neste artigo, apresentaremos os resultados e a discussão da primeira categoria "Do que é ser professor e formador de professores" a partir da percepção dos coordenadores de área do PIBID/UFOP.

\section{RESULTADOS E DISCUSSÃO}

A organização, categorização e análise de conteúdos foram estabelecidas por meio da fala dos sujeitos, buscando compreender as percepções dos atores sociais, na relação entre a formação e a prática docente. Desta forma, elaboramos na pesquisa três categorias, a saber: Do que é ser professor e formador de professores; Do PIBID como lócus de formação e Das práticas docentes na formação de professores.

Os questionários permitiram que fizéssemos uma análise do perfil dos participantes. Deste modo, entrevistamos sete homens e seis mulheres, compreendendo a faixa etária entre 36 a 60 anos.

Em relação a formação inicial cursada entre 1988 a 2004, onze participantes realizaram em universidades federais, uma universidade estadual e outra em faculdade privada. Ainda em relação a este aspecto, identificamos que todos os participantes possuem mestrado em universidades públicas, sendo que doze em universidades federais e um cursou em universidade estadual. Do total de coordenadores de área, onze destes, possuem doutorado e, dois 
estão em doutoramento. Assim como sete fizeram também pós-graduação lato sensu buscando áreas de interesse e suporte na prática profissional. Notamos que todos os coordenadores possuem uma formação bastante qualificada.

Em relação às experiências docentes, cinco foram professores na educação infantil, onze foram professores no ensino fundamental e dez no ensino médio. Todos foram professores na graduação e nove na pós-graduação. Observamos, assim, que todos possuem uma sólida experiência na docência.

Os coordenadores de área se graduaram em áreas distintas sendo: três em Letras, três em Pedagogia e, um em cada área específica: Química, Matemática, Música, Artes Visuais, História, Educação Física e Ciências Biológicas.

Nas entrevistas, seis coordenadores de área afirmaram que seu interesse pela docência foi desde a escolha pelo curso de licenciatura e sete mencionaram que o interesse surgiu de acordo com as experiências, após o início da prática profissional alinhada ao momento em que cursou a licenciatura. Já o coordenador da área de História, destacou que percorreu a área de formação de professores quando se tornou professor no ensino superior.

Em relação aos cursos de formação inicial e sua influência em se tornar professor, os coordenadores das áreas de Música e Teatro afirmaram que foram insuficientes, devido à escolha do curso ser o bacharelado e, somente após o mestrado, terem ingressado na área da educação.

Três coordenadores das áreas de Educação Física, Pedagogia/Inclusão e História salientaram a relevância dos estudos da formação inicial para o exercício da docência. Oito coordenadores das áreas Interdisciplinar em Ciências, Pedagogia/Alfabetização, Letras 1, Interdisciplinar em Literatura Afro-brasileira, Letras 2, Química, Pedagogia/EJA e Matemática reconheceram a importância à formação inicial, no entanto, reforçaram que ela não prepara de forma suficiente mas, fornece elementos para a construção de uma formação sólida como também, o contato inicial com a educação que será aprimorada com a formação continuada.

$\mathrm{Na}$ literatura do campo de formação de professores, verificamos que os professores foram formados a partir de concepções diferentes a medida do seu contexto de formação e passaram por transformações em relação a identidade, formação e profissão (DINIZ-PEREIRA, 2007).

Dessa forma compreendemos que os coordenadores de área foram formados através de concepções de cursos e de formação oriundas do seu tempo histórico e social. Garcia (2009, p. 13) salienta que "ser um bom professor pressupõe um longo processo". Assim há de se considerar que professores e formadores de professores quando licenciandos que chegam às instituições de formação inicial, que se tornarão professores, possuem repertório escolar e conhecimento prévio acerca da docência. Desta maneira, a formação é construída de maneira contínua por meio das agências formadoras como a escola e a universidade.

Em relação à formação continuada, oito coordenadores das áreas de Música, Pedagogia/Alfabetização, Letras 1, Teatro, Letras 2, História, Química e Pedagogia/EJA afirmaram que os cursos de pós-graduação os auxiliaram como formadores de professores a partir de elementos que propiciaram a reflexão e o diálogo sobre a educação.

Já quatro coordenadores das áreas Interdisciplinar em Ciências, Educação Física, Pedagogia/Inclusão e Interdisciplinar em Literatura Afro-brasileira afirmaram que os cursos de pós-graduação contribuíram em partes, destacando aspectos como a formação teórica, os exemplos que tiveram de professores e o aprofundamento a partir da pesquisa. O coordenador da área de Matemática afirmou que a pós-graduação não contribuiu, devido aos cursos serem relacionados à pesquisa e a área bem específica.

Os coordenadores de área, contaram como ocorreu a entrada no magistério, enquanto formadores de professores. Seis coordenadores das áreas de Música, Pedagogia/Alfabetização, Teatro, História, Química, Pedagogia/EJA e Matemática mencionaram que tiveram o contato com universidades públicas, três em universidades privadas e, os coordenadores das áreas Interdisciplinar em Ciências, Interdisciplinar em Literatura Afro-brasileira e Pedagogia/Alfabetização trabalhavam em ambas instituições (pública e privada).

Dois coordenadores das áreas de Educação Física e Letras 1 destacaram o contato a partir de disciplinas lecionadas no ensino superior. A trajetória inicial da coordenadora da área de Pedagogia/Inclusão foi por meio de cursos de pós- 
graduação lato sensu relacionado à alfabetização e, em seguida em universidade pública. Já o coordenador da área de Letras 2 relata o início no magistério a partir de cursos de formação de professores, em parceria com a prefeitura de Belo Horizonte. A experiência docente no ensino superior é, notadamente, constituída por experiências enquanto aluno e professor.

Desta maneira, as trajetórias dos coordenadores de área foram importantes dentro do processo de se constituir professores e formadores de professores. As aproximações com as disciplinas da licenciatura ocorreram de diferentes maneiras, como: durante a graduação e a pesquisa de mestrado e de doutorado e por meio do concurso que prestaram para atuarem como professores do ensino superior.

Perguntamos na pesquisa, o que consideram ser ensinar e como e onde o formador aprende a ensinar. Desta maneira, a maioria das respostas foram relacionadas à perspectiva dialógica, preceituada por Freire (1996). Considerando isto, organizamos o quadro a fim de sistematizar as respostas dos participantes:

Quadro 1. O que é ensinar, como e onde o formador aprende a ensinar

\begin{tabular}{|c|c|c|}
\hline $\begin{array}{ll}\text { Coordenador } & \text { de } \\
\text { área/Subprojeto } & \end{array}$ & Ensinar é: & O formador aprende a ensinar: \\
\hline Audineta (Música) & Interagir com foco & Aprende ensinar, ensinando. \\
\hline $\begin{array}{l}\text { Wilson (Interdisciplinar } \\
\text { em Ciências) }\end{array}$ & Criar oportunidade de aprendizagem. & $\begin{array}{l}\text { Aprende a ensinar com a } \\
\text { indissociabilidade da teoria e da } \\
\text { prática, se retroalimentando. }\end{array}$ \\
\hline $\begin{array}{l}\text { Miguel } \\
\text { (Pedagogia/Alfabetização) }\end{array}$ & $\begin{array}{l}\text { Planejamento coletivo de um } \\
\text { determinado conhecimento numa } \\
\text { perspectiva de formação. }\end{array}$ & - \\
\hline Flávia (Letras 1) & $\begin{array}{l}\text { Conhecer bem o seu objeto e traçar } \\
\text { estratégias para que o aluno } \\
\text { compreenda. }\end{array}$ & Aprende na prática. \\
\hline Lúcio (Educação Física) & Ensinar é um ato de amor. & $\begin{array}{l}\text { Aprende a ensinar em qualquer } \\
\text { situação. }\end{array}$ \\
\hline $\begin{array}{l}\text { Maria } \\
\text { (Pedagogia/Inclusão) }\end{array}$ & Facilitar o conhecimento para o outro. & $\begin{array}{l}\text { Aprende pelos modelos que } \\
\text { teve e pelos seus percursos de } \\
\text { formação e se transformando. }\end{array}$ \\
\hline Helton (Teatro) & $\begin{array}{l}\begin{array}{l}\text { Compromisso com o outro de } \\
\text { descoberta. }\end{array} \\
\end{array}$ & Na relação com o outro. \\
\hline $\begin{array}{lr}\text { Renata } & \text { (Interdisciplinar } \\
\text { em } & \text { Literatura } \\
\text { Afrobrasileira) } & \end{array}$ & $\begin{array}{l}\text { Ensinar a ser professor na própria } \\
\text { profissão (mostrando que gosta de ser } \\
\text { professor) }\end{array}$ & $\begin{array}{l}\text { Na sua profissão (mostrando } \\
\text { que gosta de ser professor) e } \\
\text { buscando formação nas } \\
\text { universidades. }\end{array}$ \\
\hline Jonatas (Letras 2) & - & $\begin{array}{l}\text { Aprende na prática, é aprendiz o } \\
\text { tempo todo. }\end{array}$ \\
\hline Oleir (História) & É pensar e programar o aprender. & $\begin{array}{l}\text { Aprende durante a sua } \\
\text { trajetória profissional. }\end{array}$ \\
\hline Deise (Química) & $\begin{array}{l}\text { Ter a perspectiva teórica e prática } \\
\text { alinhadas com uma discussão ampla } \\
\text { da educação. }\end{array}$ & $\begin{array}{l}\text { Aprende na educação básica e } \\
\text { nas experiências enquanto } \\
\text { alunos. }\end{array}$ \\
\hline $\begin{array}{l}\text { Dorcelina } \\
\text { (Pedagogia/EJA) }\end{array}$ & É uma troca entre sujeitos. & $\begin{array}{l}\text { Aprende pelo conhecimento da } \\
\text { área e o entendimento dos } \\
\text { sujeitos. }\end{array}$ \\
\hline Natércio (Matemática) & Conhecer o conteúdo e agir sobre ele. & $\begin{array}{l}\text { Ensinando, e se colocando no } \\
\text { lugar dos alunos para conseguir } \\
\text { perceber como eles } \\
\text { compreendem a partir da } \\
\text { realidade própria deles. }\end{array}$ \\
\hline
\end{tabular}

Fonte: As autoras. 
Desta maneira, percebemos pela sistematização das respostas que os coordenadores de área possuem uma visão dialógica e democrática do processo de ensino e aprendizagem, a partir dos preceitos de Freire (1996, p. 122), compreendendo que esse processo envolve "o educador com o educando e não sobre ele". Dessa forma, destacamos que o entendimento comum do grupo é importante para a superação da racionalidade técnica e do entendimento do "professor como detentor do saber" abrindo o espaço para uma formação horizontal e humanizada.

A formação teórica e prática não podem estar desalinhadas do contexto do sujeito, como García (2009) esclarece, o docente vivenciou durante a sua vida, modelos de formação durante a sua trajetória na educação básica como estudante, passando por uma transformação de um passado como aluno e para um futuro como professor, que influencia na sua atuação profissional, na sua concepção de docência e que se desdobra em suas práticas cotidianas em sala de aula.

Assim, é primordial a construção de um espaço de formação articulado com a atuação profissional. Nóvoa (2017) afirma, é fundamental "devolver para os professores a formação de professores", ou seja, articular os campos de formação entre a universidade e a escola, pautada na profissionalização. Como Nóvoa (2017, p. 1115) destaca "é na escola e no diálogo com os outros professores que se aprende a profissão", para que a mesma aconteça em seu exercício.

Desta maneira, acreditamos que o PIBID seja uma possibilidade de construção do novo lugar de formação em diálogo com a profissionalização. A formação inicial é de suma importância, no entanto, não devemos desconsiderar que a formação é permanente e, o coordenador de área, mesmo que seja professor no ensino superior e, tenha um alto grau de conhecimento e formação mais aprofundada, pode enriquecer ainda mais a sua própria formação e prática docente quando acompanha e participa dos momentos de formação em diálogo com a escola de educação básica.

Conforme aponta Gatti (2008), a formação continuada está ligada ao progresso do setor educacional por meio da cooperação e pelo aprofundamento profissional. Nesse sentido, é necessário que a educação seja permanente, rompendo com a perpetuação da lógica de modelos pedagógicos de memorização e com o antagonismo entre a teoria e a prática, acentuado pelo modelo da racionalidade técnica.

Desta maneira, como apontam Saviani (2009) e Mizukami (2005), o formador de professores contribui para a concepção do professor como detentor do saber, a partir dos paradigmas da racionalidade técnica, quando desconsidera a aprendizagem e os sujeitos, facilitando a continuidade desse modelo que repercute na formação e constituição de professores da educação básica:

Os formadores de
professores, com formação
e atuação próprias da
concepção de processos
formativos orientados pelo
paradigma r da
racionalidade técnica, são
os mesmos que irão
oportunizar processos
formativos sob uma nova
visão (MIZUKAMI, 2005, p.
7).

Em virtude disso, Mizukami (2005) enfatiza a importância de romper com o ciclo de reprodução das práticas da racionalidade técnica. Nesse sentido, vislumbramos que o PIBID é uma oportunidade de criar um novo lugar de formação que seja um espaço híbrido, como aponta Rodrigues (2016), possibilitando a formação mútua entre professores. Esse espaço como mencionado por Nóvoa (2009, p. 33) é um espaço coletivo de formação, denominado como "terceiro espaço de formação".

O PIBID, como espaço coletivo de formação, tem como princípio estruturante o alinhamento entre a teoria e a prática e o diálogo mais horizontal e humanizado na construção da profissão docente, não pressupõe sobreposições de saberes, pois contribui para o entendimento da diversidade de saberes e experiências, rompendo com a separação entre os elementos da prática profissional e os da formação teórica.

Assim, acreditamos que o espaço de formação mútua reforça a responsabilidade quanto à sua própria formação. Além disso, no terceiro lugar de formação, como afirma Nóvoa (2009) é onde ocorre os investimentos para a construção da profissão e do conhecimento 
profissional docente que são pautados a partir dos vieses teóricos- metodológicos.

Freire (1996) colabora, nesse sentido, quando aponta a condição de inacabamento dos sujeitos e a consciência da necessidade de continuar a aprender. Nesse sentido, se reconhecer como sujeito inacabado, na condição de ser condicionado, é uma possibilidade de tornar-se consciente e ultrapassar essa condição (FREIRE, 1996, p. 53).

Deste modo, diante do contato com a experiência prática, o coordenador de área tem a possibilidade de reflexão sobre a sua condição de "inacabamento e inconclusão" (FREIRE, 1996), que perpassa a sua formação e atuação profissional e, como professor e formador de professores pode modificar tais práticas, repensar e refletir diante de sua própria formação e atuação profissional.

A constituição do ser professor é uma construção que decorre do ciclo de vida profissional como afirma Huberman (1992), como também se constitui através dos saberes plurais ressaltados por Tardif (2014) e, ainda perpassa a capacidade de refletir sobre a reflexão, apontado por Schön (1991).

Esta pesquisa mostrou que todas as trajetórias formativas possibilitaram a escolha consciente pela área de atuação na docência, como também se objetivaram em opção pela docência após vivenciar este lugar. Contudo, mesmo que alguns desses, não tenham optado inicialmente pela profissão, todos os seus percursos de vida profissional e pessoal culminaram na docência.

Os coordenadores de área passaram por uma formação, que muitas vezes, era conteudista e pouco contribuiu para a docência, como Mizukami (2005) afirma, pois muitos formadores "foram orientados pelo paradigma da racionalidade técnica", contudo, os mesmos estão no processo de formação de outros professores e deste modo, são necessárias reflexões e práticas para romper com essa lógica.

Assim, como Nóvoa (2009) destaca, existe um "consenso discursivo" sobre as medidas e princípios no que se refere à formação de professores e o seu desenvolvimento profissional. Em virtude disso, repensar e romper com as lógicas pautadas na racionalidade técnica e não reproduzir esses paradigmas na formação de novos professores são essenciais.
Ao pensarmos em perfis de formadores, há inúmeros pontos a serem considerados e é difícil traçar algo nesta perspectiva, principalmente por remeter a uma lógica maniqueísta. No entanto, Nóvoa (2009, p. 28) afirma que existem alguns apontamentos simples, que podem colaborar com a reflexão sobre o perfil de professores. Desta maneira, a partir das colocações dos coordenadores de área do PIBID/UFOP, trouxemos apontamentos importantes para essa discussão, sobre como se constitui o formador de professores e, elementos que podem trazer qualidade para a formação e a profissão docente.

Nóvoa (2009) apresenta cinco disposições que acredita ser essenciais à definição dos professores na atualidade, primeiramente 0 conhecimento ligado ao "saber o que se ensina" a fim de conduzir à aprendizagem dos alunos.

Em segundo lugar, a cultura profissional destacando as trocas e o diálogo entre colegas mais experientes, reflexões das práticas, avaliações e mudanças que levam à progressão da aprendizagem da profissão.

Em terceiro lugar, o tato pedagógico, que perpassa a dimensão da pessoalidade do professor, ligado a construção da sua própria profissão e a sensibilidade individual para construir uma relação de troca com seus alunos de forma respeitosa.

Em quarto lugar, Nóvoa (2009) destaca o trabalho em equipe como essencial, pois reforça a dimensão coletiva da profissão envolvendo os sujeitos em projetos na instituição e por fim, em quinto lugar, o compromisso social, que está ligado ao cumprimento da função social, pedagógica e política da escola.

Concomitantemente com essas disposições elencadas por Nóvoa (2009, p. 32), o autor menciona três momentos essenciais de formação para se constituir professores, como a graduação em uma determinada disciplina científica, o mestrado que compreende uma forte perspectiva pedagógica, didática e profissional e o estágio probatório que colabora através da indução profissional.

Deste modo, Nóvoa (2009) e Imbernón (2009) propõem que as práticas na profissão possam ser lugares de reflexão e formação fundamentais. Além da profissionalização imersa na escola pelos próprios professores, a relação interpessoal e de comunicação que envolve a dimensão da pessoalidade do professor, o 
trabalho em equipe enfatizado pelo exercício coletivo da profissão e o comprometimento com a dimensão pública da formação de professores.

A seguir apresentaremos um quadro

sistematizando componentes que os

coordenadores de área do PIBID/UFOP, apontaram nas entrevistas, sobre elementos que caracterizam a qualificação do formador de professores:

Quadro 2. Ser um bom formador de professores

\begin{tabular}{|l|l|}
\hline Coordenador de área & Apontamento destacado na entrevista sobre "Ser um bom formador" \\
\hline $\begin{array}{l}\text { Dorcelina } \\
\text { (Pedagogia/EJA) }\end{array}$ & Escutar o aluno; dialogar de forma e valorizar o conhecimento do outro. \\
\hline $\begin{array}{l}\text { Miguel } \\
\text { (Pedagogia/Alfabetização) }\end{array}$ & Dialogar, articular teoria e prática e se atualizar. \\
\hline $\begin{array}{l}\text { Maria } \\
\text { (Pedagogia/Inclusão) }\end{array}$ & $\begin{array}{l}\text { Ter a dimensão profissional, mostrar a realidade e ensinar com o } \\
\text { exemplo. }\end{array}$ \\
\hline Deise (Química) & Ter conhecimento, estar comprometido com a formação de professores. \\
\hline $\begin{array}{l}\text { Flávia (Letras 1) } \\
\text { Jonatas (Letras 2) }\end{array}$ & $\begin{array}{l}\text { Estar comprometido com a formação de professores e com a dimensão } \\
\text { política e pública. }\end{array}$ \\
\hline $\begin{array}{l}\text { Renata (Interdisciplinar } \\
\text { em } \\
\text { Afrobrasileira) }\end{array}$ & $\begin{array}{l}\text { Estar disposto a se repensar, acreditar na profissão, ter conhecimento } \\
\text { sobre a área. }\end{array}$ \\
\hline $\begin{array}{l}\text { Wilson (Interdisciplinar } \\
\text { em Ciências) }\end{array}$ & Contribuir para a formação profissional e com a formação de professores. \\
\hline Oleir (História) & $\begin{array}{l}\text { Acompanhar o debate educacional, com a escola, estar comprometido } \\
\text { com a aprendizagem. }\end{array}$ \\
\hline Helton (Teatro) & $\begin{array}{l}\text { Ter comprometimento com a própria formação, com a aprendizagem e } \\
\text { com o aspecto social e cultural. }\end{array}$ \\
\hline Natércio (Matemática) & Entender como os alunos aprendem e ser capaz de ensiná-los. \\
\hline Audineta (Música) & Escutar o aluno e dialogar. \\
\hline Lúcio (Educação Física) & $\begin{array}{l}\text { Ter consciência que não sabe tudo, ter conhecimento da área e buscar } \\
\text { novas práticas. }\end{array}$ \\
\hline
\end{tabular}

Fonte: As autoras.

Deste modo, os coordenadores de área do PIBID/UFOP reforçaram nas entrevistas, que os formadores precisam de algumas características, para tornarem sua prática docente mais qualificada. Considerando o aspecto profissional, como salienta Nóvoa (2009), é preciso ter cuidados durante a formação de professores, sobretudo nos primeiros anos da docência:

Nestes anos em que transitamos de aluno para professor é fundamental consolidar as bases de uma formação que tenha como referência lógicas de acompanhamento, de formação-em-situação, de análise da prática e de integração na cultura profissional docente (NÓvOA, 2009, p. 38).
Nesse contexto, destacamos que a cultura profissional é importante na dimensão da formação do professor. Em virtude disso, consideramos que o formador de professores deve estar em consonância com os elementos apontados anteriormente por Nóvoa (2009), para garantir e articular a formação sólida dos futuros professores, o acompanhamento e a integração na prática profissional. Como o coordenador da área Interdisciplinar em Ciências afirma, existe alguns princípios ligados à formação profissional que precisam ser considerados pelo formador: ele precisa atuar como um indivíduo que... cria essas oportunidades de aprendizagem... a partir de ... dos recursos que ele tem né... da sua experiência 
tanto como formador como professor né ... e de como... e... um indivíduo que traz... alguns... determinados recursos teóricos e metodológicos para... os alunos entenderem que... que esse... essa formação... é uma formação profissional... né... então um bom formador de professores ele precisa entender... que ele está preparando profissionais... né... e quando ele prepara profissionais... ele precisa capacitar esses profissionais para as demandas que a profissão exige... então nesse sentido... que eu considero que... para ser um bom formador... a gente tem que ter clareza de alguns princípios...Wilson

(Interdisciplinar em Ciências)

Deste modo, o formador de professores, segundo o coordenador da área Interdisciplinar em Ciências, precisa considerar que ele está contribuindo para a construção do profissional e da sua atuação na profissão. $O$ que se reforça nos apontamentos de Nóvoa (2009) sobre as disposições essenciais dos professores de hoje caracterizados pela cultura profissional, o conhecimento e o compromisso social.

Ainda nesse aspecto, temos outros elementos importantes a serem considerados, como a exposição da coordenadora da área de Química, onde afirma ser importante o aspecto do conhecimento e estar comprometido com a formação de professores:

é uma pessoa que... tem uma formação... tem que ter uma formação teórica sólida... consistente...que não seja incoerente assim...aquela mistureba de linhas sabe... mas que também... consiga entender as políticas públicas de educação... a sala de aula... não no idealismo a sala de aula mas ele discuta com os estudantes... aquela sala de aula que existe...em várias perspectivas... inclusive de modificar aquela sala de aula que existe... então isso pra mim...porque...

infelizmente eu vejo que existem...algumas pessoas que atuam...e ela acha que...a pesquisa vai ser o fundamental...né...então... você tem que ter... a pressão que existe na Universidade... você tem que produzir... a produção de artigos científicos... e não de pensar a sala de aula... então a sala de aula é um pretexto para arranjar algum artigo para produzir... e aí vai trabalhando na formação de professores pensando... em formar pesquisadores...e não em formar professores... é...então eu acho que isso é um problema sério que a gente tem nos cursos de licenciatura... então a gente tem professores atuando... não que não possa acontecer a formação de um pesquisador... mas, você está trabalhando na formação de professores não na formação de um pesquisador... então a sala de aula...ele não é um mero objeto para você publicar um artigo... ele é um objeto para você problematizar a educação pública no País... e pensar em possibilidades...então... isso para mim... é um grande problema da Universidade...Deise

(Química)

Assim, a coordenadora da área de Química destaca que a formação de professores nos cursos de licenciatura, devem estar ligados aos processos da ação docente e não da pesquisa, desta forma, menciona que existem alguns equívocos em relação à formação e o objetivo da 
formação na licenciatura, quando os formadores estão interessados em formar apenas pesquisadores e não contribuem com a formação de professores. Assim como a coordenadora da área de Pedagogia/Inclusão destaca, é importante que o formador de professores consiga mostrar aos futuros professores a importância do seu trabalho como professor:

como um bom formador de professor... é uma pessoa que... consegue passar para esse futuro professor uma dimensão da importância do trabalho dele... que consegue passar para esse futuro professor uma visão da docência que não é romantizada né... que é uma visão real... que consegue tirar de dentro dele é....aquilo que ele tem de melhor né para atuar como professor... é aquele que consegue mostrar possibilidades de atuação é... consegue mostrar a possibilidade de crescimento para além da graduação...e sobretudo aquele que consiga vincular esse futuro professor à docência... que consiga fazer ele acreditar... na profissão... construir segurança... eu acho que é por aí.. Maria (Pedagogia)

Aspectos como o comprometimento com a formação continuada, também são elementos que emergem nas colocações dos participantes:

eu considero... primeiro... A pessoa ter humildade... A pessoa saber que ela não sabe tudo... É o primeiro ponto... Então a todo o momento... A todo instante... Eu preciso estudar... Então para ser um bom professor eu preciso abrir a minha mente... E compreender que eu sei determinada quantidade de coisas e que junto com você a gente vai saber mais... Lúcio

(Educação Física)
198

Ele tem que estar comprometido com a sua própria formação... E tem que se entender como um... Uma pessoa em processo de formação contínuo... Acho que isso é fundamental... Porque aí você está... Aberto às demandas e... (Falha na chamada do Skype) está me ouvindo agora? [sim...você estava falando que ele tem que estar comprometido com o seu processo de formação contínua né...] sim... quer dizer... nem só com o processo formal... com a formação continuada como as pessoas falam no sentido de... formação de curso e coisa e tal... ele tem que se sentir como sujeito que está em processo... Que está incompleto ou seja... Ele está se construindo a cada experiência... Experiência que ele tem... Helton (Teatro)

Repensar sempre a sua prática pedagógica também eu acho que não dá pra ser um formador... se a gente também não repensar a nossa própria prática... então a gente deve estar sempre se questionando e se abrir também aos que os alunos nos dão de retorno... para que a gente se atualize se reforme, se recicle, para que a gente continue aprendendo... então isso pra mim é fundamental... está aberta aos deslocamentos... que as coisas naturalmente e historicamente vão acontecendo... né... então... acho isso pra mim é importante, eu estar aberta e eu me mostrar aberta a isso... para que talvez isso... mostre que a 
gente como formador e como professores depois... a gente tem que estar sempre com disposição de aprender também né... Renata (Interdisciplinar em Literatura Afrobrasileira)

Os referidos coordenadores reforçaram a importância da formação permanente, onde o professorado assuma "ser sujeito da formação", reconhecendo o seu próprio protagonismo e se tornando aprendizes na sua formação e no ambiente que atuam (IMBERNÓN, 2009). Desta maneira, se reconhecer como aprendiz possibilita a transformação, como aponta a coordenadora da área Interdisciplinar em Literatura Afro-brasileira na sua prática pedagógica.

Outra dimensão de grande relevância que apareceram nas falas dos participantes, foram os elementos do conhecimento, "conhecer bem aquilo que ensina" e o tato pedagógico, relacionado ao respeito, à conquista dos alunos e a condução entre o ensino e a aprendizagem, os coordenadores das áreas de Música, Matemática e Pedagogia/Alfabetização reforçam esses aspectos:

é aquele que... escuta...o seu aluno... que sabe dialogar com ele... naquele momento que aquele aluno está vivendo... Audineta (Música)

então eu acredito que um bom formador é aquele que... que é capaz de entender a forma com que os alunos... compreendem o conteúdo e como que eles agem sobre ele... porque para você conhecer... para você apropriar... você precisa conhecer e agir sobre ele... então você tem que conseguir fazer com esses alunos... com que eles haja sobre aquele conhecimento...Natércio

(Matemática)

sim...tem aspectos... que a gente pode pensar... pensar que um bom professor é aquele que consegue dialogar bem com os seus alunos...é um professor que consegue pensar o conteúdo que vai trabalhar...é...e articular isso com a realidade né...desses alunos...ou seja, fazendo uma articulação entre esses conteúdos e a realidade que estes alunos vivenciam... é aquele que consegue abrir o espaço para o diálogo dentro da sala de aula...né...ou seja, que sai de uma lógica transmissiva para uma lógica muito mais dialógica...eu acho que é alguns...esses pontos...por exemplo, podem caracterizar um professor...eu não diria que seria um bom professor... eu diria que seria um professor com uma certa qualidade...né... Miguel (Pedagogia)

Como observamos pelas falas dos coordenadores de área, há uma aproximação com o elemento do tato pedagógico mencionado por Nóvoa (2009), em consonância com a ruptura da formação baseada na racionalidade técnica pontuada por Mizukami (2005), pois ressaltam a importância do diálogo e a troca entre os sujeitos da ação pedagógica, além de considerar os saberes do educando e trabalhar com a perspectiva da aprendizagem e não só do ensino.

Em virtude disso, salientamos a importância do ensino e da aprendizagem ocorrerem de forma indissociável, assim como a teoria e a prática como indicam as falas dos coordenadores de área e expressado pelo coordenador da área de Letras quando menciona a cultura profissional alinhado ao conhecimento neste processo dialético:

Olha... eu acho que é um sujeito que dialoga muito com a prática... que faz com que...que pensa... que vê o que tá acontecendo com as escolas... acompanha um pouco a realidade das escolas... tem 
uma... leitura atualizada cerca de documentos oficiais...acerca da área...a...se ele... se ele conhece né... a sala de aula... ele tem experiência de sala de aula... é muito importante... Jonatas (Letras)

A partir dos apontamentos, percebemos que o grupo de coordenadores de área do PIBID/UFOP, estão alinhados com os princípios da formação de professores e com os objetivos do PIBID, pois os mesmos relacionam o comprometimento com a educação pública, com a formação de professores e demonstram estarem em constante exercício de avaliação da sua própria prática, buscando a formação permanente.

Além disso, o PIBID foi uma experiência formativa inovadora para os participantes que puderam vivenciar essa experiência na UFOP:

eu acho que era muito isso sabe... de planejar é... a partir da realidade de cada turma... eu acho que isso foi muito bacana... e dar liberdade para os bolsistas criarem... inovarem... eu sempre incentivei muito isso...que eles levassem o novo... para dentro da escola né... que eles desestabilizassem aquilo que já tava muito cristalizado lá... Maria (Pedagogia)

Fundamentais mesmo foi assim, pensar a aula de história pra além é ... dos materiais mais comuns como livro didático e tal, e uma prática constante de investigação e inovação metodológica das aulas, uso de outras linguagens é, é música, cinema etc. Oleir (História)

outra questão é... a possibilidade que os alunos, eles tiveram de planejar ações educativas, que aconteceram nas escolas... tendo uma perspectiva que a gente tentava de ser... ações mais transversais né... e que algumas, deram... muito bons resultados né e dentro dessa perspectiva, quanto de se reconhecer como professor... mas também se reconhecer como autor da sua prática... então nesse sentido eu acho que as... atividades, elas foram as mais relevantes dentro do PIBID ciências... Wilson (Ciências)

Como os mesmos destacaram, as experiências dentro dos subprojetos foram singulares, no sentido de que os coordenadores de área puderam desenvolver o trabalho com cada turma de forma diferente. Favoreceram, ainda, a criação e novas formas de conduzir suas aulas.

\section{CONCLUSÕES}

A formação de professores exige um constante repensar. Desde antes da formação inicial até a formação continuada. O professor, continua em processo de formação permanente e se transforma, aprendendo com outros sujeitos e interagindo em ambientes diversos.

Em virtude da trajetória de formação inicial, percebemos que não foram todas as experiências nas instituições de ensino superior que potencializaram uma formação baseada no rompimento da racionalidade técnica, no aprofundamento de metodologias e uma discussão mais ampla do campo educacional.

Contudo, formação inicial é um período importante para a constituição do professor, ao mesmo tempo, que a vivência profissional. Nesse sentido, todos os coordenadores de área em contato com a sala de aula, puderam reforçar a escolha profissional.

A formação continuada, entretanto, para muitos foi uma importante etapa, em que os coordenadores de área puderam aprofundar os conhecimentos em áreas de interesse, como também, puderam aprofundar o conhecimento pedagógico, de pesquisa, além de potencializar discussões mais amplas que atravessaram o seu percurso formativo.

O PIBID, portanto, complementou a experiência profissional, se configurando como 
uma importante estratégia formativa, no qual trocaram experiências com professores em níveis de formação diferentes, acrescentaram à sua trajetória. O PIBID foi uma experiência formativa inovadora que segundo os próprios entrevistados, foi caracterizada como singular.

Observamos que para os participantes da pesquisa, ser professor e ser formador de professores é algo que se complementa, a medida do percurso de formação e atuação profissional pois, através desse espaço, é possível realizar reflexões em diálogo com a teoria e a prática.

A transformação do campo da formação de professores, debatido no campo de formação de professores, perpassa o rompimento da dicotomia da teoria e prática; a valorização da profissão docente considerando o professor como produtor de conhecimento e não reprodutor de práticas mecânicas ou técnicas conteudistas e sem crítica, assumindo o seu próprio protagonismo com autonomia.

Desta maneira, ao passo que se torna formador de professores deve-se ter o comprometimento com os ideais da educação e, permitir-se repensar sua própria formação, no sentido de compreender-se como "aprendiz" e, buscar continuamente experiências concretas que contribuam para a sua qualificação e atuação profissional em diálogo com a educação básica. Deste modo, o PIBID é uma oportunidade de vivenciar esse lugar de aprendizagem.

Os coordenadores do PIBID/UFOP demonstraram que o PIBID colaborou para o diálogo com a formação de professores iniciantes ao passo que viabilizou o acompanhamento dos seus licenciandos no ambiente formativo da escola, professores em exercício na educação básica, assim como a reflexão de suas práticas enquanto formadores de professores.

Concluímos, com a certeza da importância de continuarmos colocando em discussão, o importante papel das políticas públicas de formação de professores e a continuidade das mesmas a fim de promoverem um espaço dialógico e horizontal.

Por meio desse espaço é possível favorecer o elo entre a universidade e a escola de educação básica para que ocorram as trocas de experiências entre professores, tendo como objetivo o desenvolvimento profissional e formativo dos sujeitos em diferentes etapas de formação seja inicial ou continuada, a fim de criar um lugar diferenciado de formação de professores que atravesse a constituição do ser professor e do ser formador de professores através de um viés de transformação social e formativa dos sujeitos.

\section{REFERÊNCIAS}

BARDIN, L. Análise de conteúdo. São Paulo: Edições 70, 2011.

DINIZ-PEREIRA, J. E. Formação de professores, trabalho docente e suas repercussões na escola e na sala de aula. Educação e Linguagem, São Paulo, v. 10, n. 15, p. 82-98, 2007. Disponível em: http://www.bibliotekevirtual.org/index.php/2013 -02-07-03-02-35/2013-02-07-03-03-11/2014-0719-06-15-59/472-el/v10n15/3715-formacao-deprofessores-trabalho-docente-e-suasrepercussoes-na-escola-e-na-sala-de-aula.html.

Acesso em: 26 nov. 2020. DOI: 10.15603/21761043/el.v10n15p82-98

FREIRE, P. Pedagogia da Autonomia: saberes necessários à prática educativa. São Paulo: Paz e Terra, 1996.

GATTI, B. A. Análise das políticas públicas para formação continuada no Brasil, na última década. Revista Brasileira de Educação, Rio de Janeiro, v. 13, n. 37, p. 57-70. jan./abr. 2008. Disponível em: . Acesso

em: https://www.scielo.br/scielo.php?script=sci artte xt\&pid=S1413-

$24782008000100006 \&$ lng=pt\&tlng=pt. 26 nov. 2020. DOI: $10.1590 /$ S1413-24782008000100006

GARCIA, Carlos, M. Desenvolvimento Profissional Docente: passado e futuro. Sísifo: Revista de Ciências da Educação, Lisboa, n. 8, p. 7-22, 2009.

HUBERMAN, M. O ciclo de vida profissional dos professores. In: NÓVOA, A. (Org). Vidas de professores. Lisboa: Porto Editora, 1992.

IMBÉRNON, F. Formação permanente do professorado: novas tendências. São Paulo: Cortez, 2009.

LÜDKE, M. O professor, seu saber e sua pesquisa. Educação \& Sociedade, Campinas, v. 22, n. 74 , p. 251-283, abr. 2001. Disponível em: https://www.scielo.br/scielo.php?script=sci artte xt\&pid=S0101$73302001000100014 \&$ Ing=pt\&tlng=pt. $\quad$ Acesso 
em: 26 nov. 2020. DOI: 10.1590/S010173302001000100014

MIZUKAMI, M. da G. N. Aprendizagem da docência: Professores formadores. Revista ECurriculum, São Paulo, v. 1, n. 1, p. 1-17, dez./jul. 2005-2006. Disponível em: https://revistas.pucsp.br/index.php/curriculum/ar ticle/view/3106/2046.

Acesso em: 01 out. 2019.

MINAYO, M. C. de L. (Org.) Pesquisa Social. Teoria, método e criatividade. 18. ed. Petrópolis: Vozes, 2001.

MINAYO, M. C. de L. (Org.). Pesquisa social: teoria, método e criatividade. 19. ed. Petrópolis, RJ: Vozes, 2016.

NÓVOA, A. Professores: Imagens do futuro presente. Lisboa, Portugal: Educa, 2009.

NÓVOA, A. Firmar a posição como professor, afirmar a profissão docente. Cad. Pesqui. [online]., São Paulo, v. 47, n. 166, p. 11061133, 2017. Disponível em: https://www.scielo.br/scielo.php?script=sci artte xt\&pid=S0100-

$15742017000401106 \& \operatorname{lng}=p t \&$ tIng=pt. Acesso em: 26 nov. 2020. DOI: L10.1590/198053144843.

ROSA, M. C.; MATOS, D. A. S. Programa Institucional de Bolsa de Iniciação à Docência na UFOP. Jundiaí, Paco Editorial: 2015.

RODRIGUES, M. U. Potencialidades do PIBID como Espaço Formativo para Professores de Matemática no Brasil. 2016. 540f. Tese (Doutorado em Educação Matemática)Universidade Estadual Paulista Júlio de Mesquita Filho, Rio Claro, 2016.

SAVIANI, D. Formação de professores: aspectos históricos e teóricos do problema no contexto brasileiro. Revista Brasileira de Educação, Rio de Janeiro, v. 14, n. 40, p. 143-155, jan./abr. 2009. Disponível em: https://www.scielo.br/scielo.php?script=sci artte xt\&pid=S1413-

$24782009000100012 \& \operatorname{lng}=p t \&$ tlng=pt. Acesso em: 26 nov. 2020. DOI: 10.1590/S1413$\underline{24782009000100012}$
SCHÖN, D. The reflective turn: case studies in and on educational practice. New York: Teachers Press, Columbia University, 1991.

TARDIF, M. Saberes docentes e formação profissional. 16. ed. Petrópolis: Vozes, 2014.

TRIVIÑOS, A. N. S. Introdução à pesquisa em ciências sociais: a pesquisa qualitativa em educação. São Paulo: Atlas, 1987. 